\title{
INVESTIGATING THE IMPACT OF DIFFERENT MODELING ALGORITHMS AND THEIR ASSOCIATED UNCERTAINTIES ON VOLUME ESTIMATION (GULLFAKS FIELD, NORTH SEA)
}

\author{
Emmanuel Umeagu \\ Centre of Excellence in Geosciences \\ and Petroleum Engineering \\ University of Benin, Edo, Nigeria. \\ Peter Onyedikachi Ibemesi \\ Centre of Excellence in Geosciences \\ and Petroleum Engineering \\ University of Benin, Edo, Nigeria.
}

\author{
Smart Osadebamwen Osarenogowu \\ Centre of Excellence in Geosciences \\ and Petroleum Engineering \\ University of Benin, Edo, Nigeria \\ Osayamen Julius Imarhiagbe \\ Energy and Mineral Resources \\ Geosciences Institute \\ RWTH Aachen University, Germany
}

Abstract- Reporting reliable results for hydrocarbon volume estimation is important for both economic analyses and making key decisions in reservoir management and development. Adequate facies and petrophysical modeling of static reservoir properties are key inputs for the derivation of a robust static reservoir model from which static volume is computed and inherent uncertainties are quantified. However, the choice of geostatistical algorithm for building the model depend on development and production maturity, degree of reservoir heterogeneity and the type, quality and amount of data. This study therefore aims at investigating the impact of the combination of stochastic and deterministic methods of property modeling on volume estimation and also perform uncertainty and sensitivity analyses to quantify uncertainties so as to aid exploration and production decision making process. Facies model were simulated/generated using both stochastic and deterministic algorithms. The resultant facies model formed an input for the petrophysical modeling process also using both stochastic and deterministic algorithms. For each combination, hydrocarbon pore volume was computed. Monte Carlo Simulation method was used to perform the uncertainty analysis where the low case (P10), mid case (P50) and high case (P90) was outputted. The results show that a combination of Sequential Indicator Simulation (facies) with Sequential Gaussian Simulation (petrophysical) captured a large range of hydrocarbon pore volume for the twenty equiprobable realizations simulated while the combination of Truncated Gaussian Simulation with trend and Gaussian Random Function Simulation gave a limited range. A combination of the deterministic algorithm gave a single estimated and more pessimistic volume. Uncertainty analysis indicated that the facies modeling process and the combination of SIS_SGS algorithm have a higher impact on volumetrics.

Keywords - Reservoir, volume estimation, uncertainties, modeling.

\section{INTRODUCTION}

Reserve Estimation is a vital part of Exploration and Production Business decision making. Acting as a "springboard" for E\&P business decisions, it encapsulates the portfolio ranking and business viability of any E\&P company's asset hence, the importance of correctly estimating volumes of reserves cannot be over-emphasized. Be that as it may, volume estimation remains a very uncertain task ${ }^{e e}$ due mainly to the heterogeneity of earth processes. To compute this volume, various algorithms, underpinned by geoscientific and engineering practices have been developed over time to reduce the possible errors associated with hydrocarbon volume estimation.

These algorithms are geostatistical computations used to delineate the properties of an asset (property modeling). These algorithms are then subjected to uncertainty and sensitivity analyses to account for the dynamics of earth processes as well as inherent uncertainties of the algorithms. The Gullfaks giant oil field lies within the Norwegian license PL 050 in block $34 / 10$ at $610 \mathrm{~N}$ and $20 \mathrm{E}$ in the Norwegian sector of the North Sea. The Gullfaks Field was discovered in 1978 and was set on production in 1986. It is one of the largest oil producing fields in Norway.

The Gullfaks field covers an area of $51 \mathrm{~km} 2$ with water depths ranging from 135 to $220 \mathrm{~m}$. It is located in the central part of the East Shetland Basin on the northern North Sea Graben 
and represents the shallowest structural element in the Tampen SPur, bounded to the east by the East Shetland platform and to the west by the Viking graben (Petterson et al., 1990). The Gullfaks Field is characterized by two structurally contrasting compartments; a western domino system with typical domino-style fault block geometry and a deeply eroded western horst complex of elevated subhorizontal layers and steep fault. Between these two zones is a modified accommodation zone (Graben System), identified as a modified fold structure.

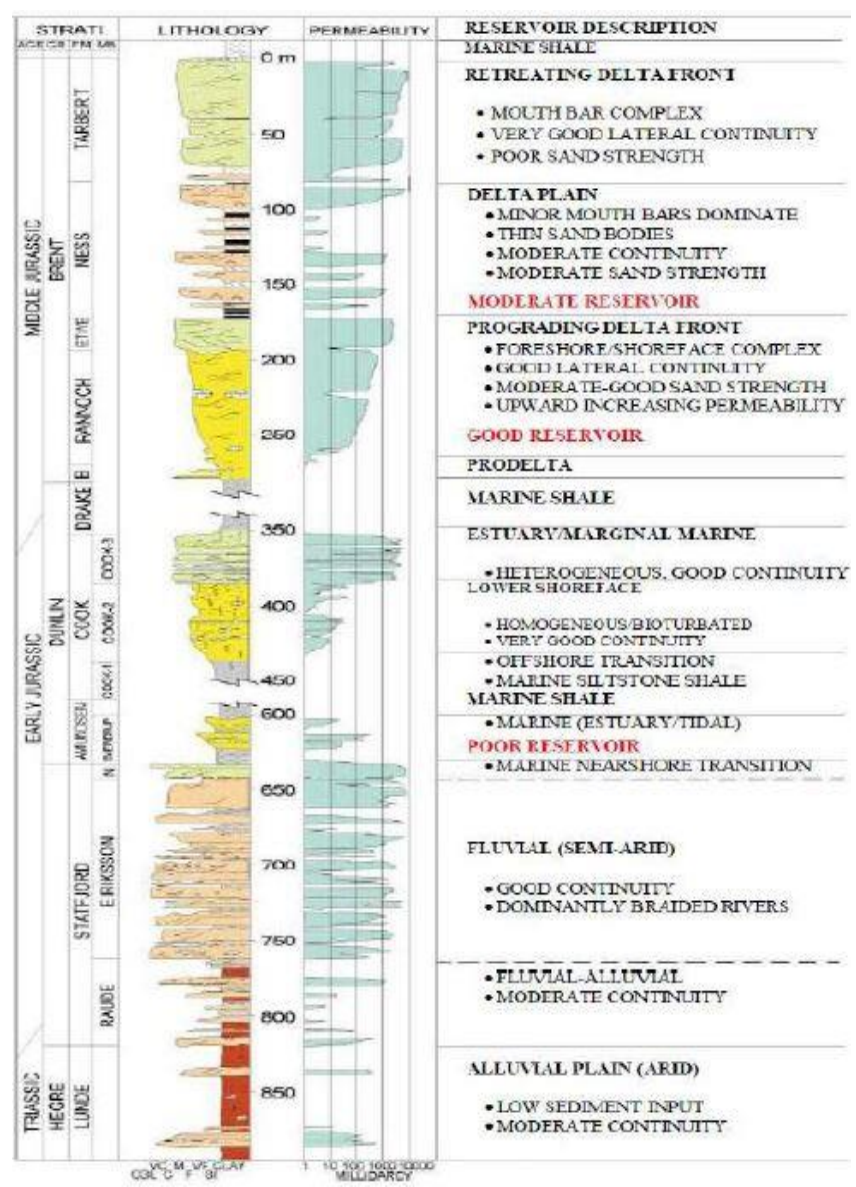

Figure 1: Composite Log display of the Gullfaks reservoirs, showing variation in reservoir quality. Modified from (Fossen et al., 1996).

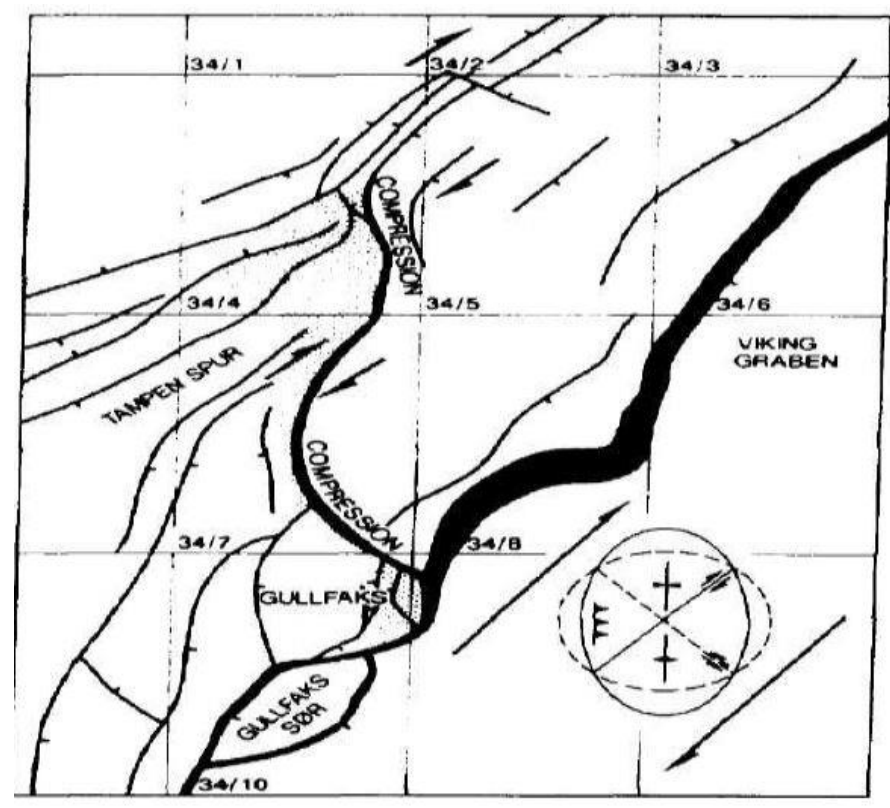

Figure 2: Structural model of the Gullfaks Field (modified after Peterson et al., 1990

Stochastic techniques are used when sparse data are present yielding hypothetical results based on the input data. They generate multiple realizations which help in understanding the degree of uncertainty in the model. Stochastic techniques honour data variability but the main pitfall is that important aspects of the data are allowed to vary randomly. Upscaled cells are not required to perform stochastic modelling. Stochastic models are divided into 2. They include the pixel based and object-based methods.

These algorithms and modelling techniques vary while modeling for continuous (petrophysical) or discrete (facies) properties. Algorithms will be discussed below in terms of discrete or continuous property.

Stochastic algorithms produce multiple equiprobable realizations while deterministic algorithms produce only a single realization. This is due to the data type incorporated by both sets of algorithms. Deterministic algorithms use only hard data which is the well data that penetrates the cells of the 3D geocellular model. In deterministic algorithms only the cells intersected by well data are assigned values (facies/petrophysical properties as seen in the well data). For stochastic algorithms on the other hand, alongside hard data, it uses soft data which serve as auxiliary conditioning data. Typical soft data corresponds to statistical and geological parameters constraining facies continuity, examples are variograms, training images, facies proportions etc. These soft data aim to reproduce the entire variability of facies and petrophysical distribution and hence multiple results generation.

Generally, deterministic methods provide a reconstruction which is unique and smooth solution aiming at local accuracy while stochastic algorithms provide a set of models with equiprobable distributions aiming at global accuracy. For this work, stochastic algorithms Sequential Indicator Simulation and Truncated Gaussian Simulation with trends and 


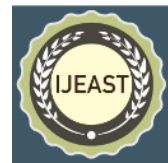

deterministic algorithm Indicator Kriging were used for the facies modeling process while Sequential Gaussian Simulation and Gaussian Random Function Simulation were the stochastic algorithms employed for petrophysical modeling with the deterministic algorithm being Co-Kriging.

\section{MEthodology}

Generally, property modeling often begins with log upscaling (scale up well $\operatorname{logs}$ ), followed by data analysis and then the property modeling proper. Scale up well log involves averaging of well $\log$ data into 3D grid cells. Well logs needed for the modeling process are upscaled into the 3D grid to assign values to cells that are penetrated by the wells. Upscaling is done because the grid cells can only be assigned a single value hence the upscaling of the well logs (lower sampling rate) into the 3D grid cells (larger sampling rate). Data analysis involves data transformation (where all data are transformed to normal distribution) and variogram analysis (a plot of variance against separation distance.

On completion of upscaling and data analysis, property modeling which involves populating the cells of a 3D geocellular reservoir model with facies and petophysical properties was then done using the aforementioned algorithms. Different combinations of these algorithms, both facies and petrophysical models were then done to produce multiple property models from whence volumes were estimated. These algorithm 'combinations' are seen below in Figure 3

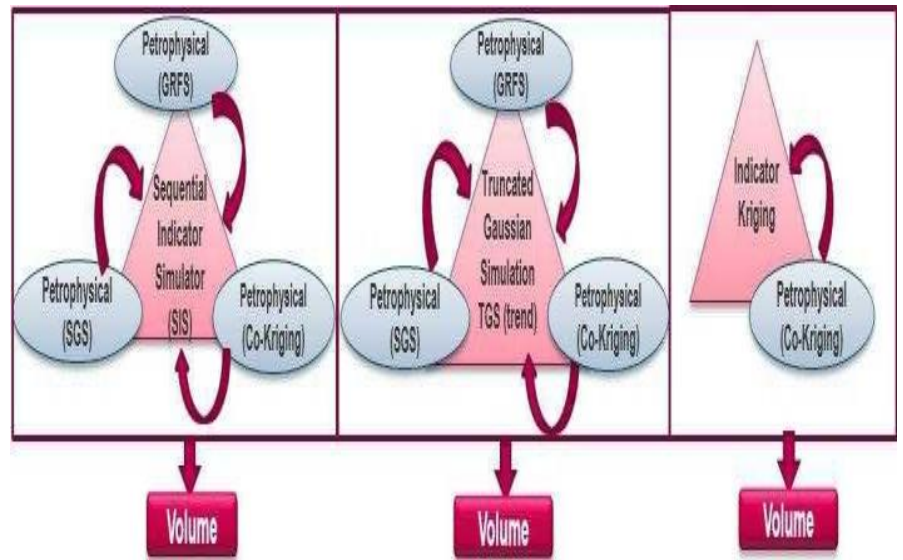

Figure 3: Chart showing volume estimation process for differe algorithm combination

With the volumes all computed, sensitivity/uncertainty analysi Here, Monte Carlo Simulation was used to run the model numeror times with a random selection from the input distributions for eac variable. The results of these numerous scenarios present worst-cas most-likely, and best-case scenarios.

\section{RESULT AND DISCUSSIONS}

Multiple facies models and subsequently petrophysical models we built from where volumes were computed. Some of the facies an petrophysical models derived are seen below. SIS was used in the early stages of the project, facies architecture, shapes and dimensions. were notyet clearly understood hence, SIS was used to generate a preliminary facies model.

The deterministic algorithm adopted for the facies modeling is the Indicator Kriging. This algorithm produced single estimated facies information output across the model reservoir without capturing multiple scenarios, hence heterogeneity and uncertainty cannot be evaluated.
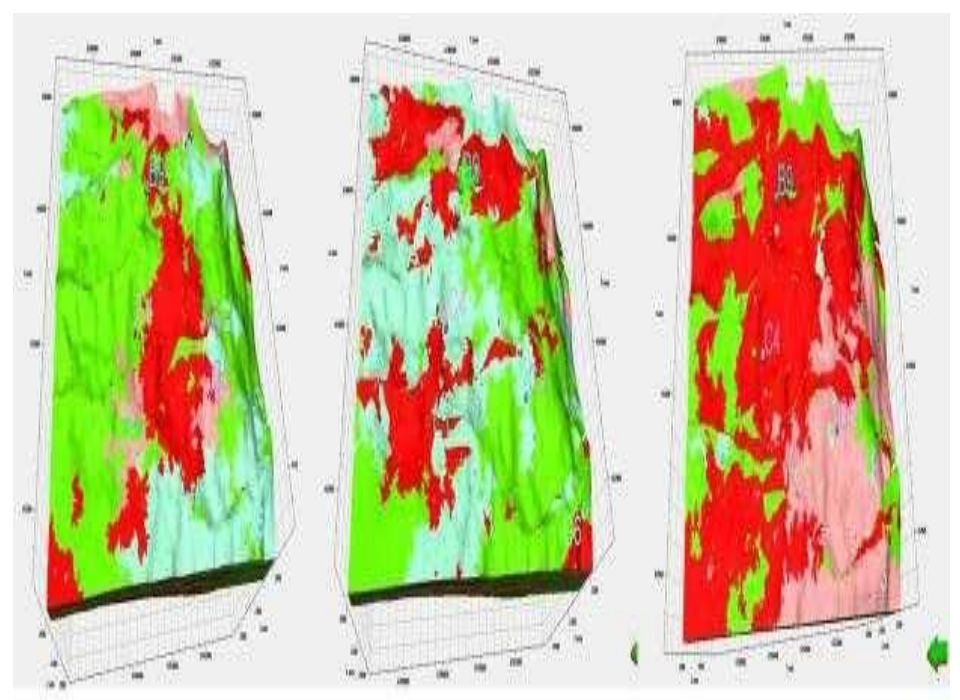

Figure 4: Sequential Indicator Simulation realizations An example of a petrophysical model

The porosity, net to gross and water saturation model of the Tarbert reservoir were simulated using facies model generated from the SIS, TGS with trend and Indicator Kriging algorithm respectively as input. This gave a prepared platform for which volume estimation was done.

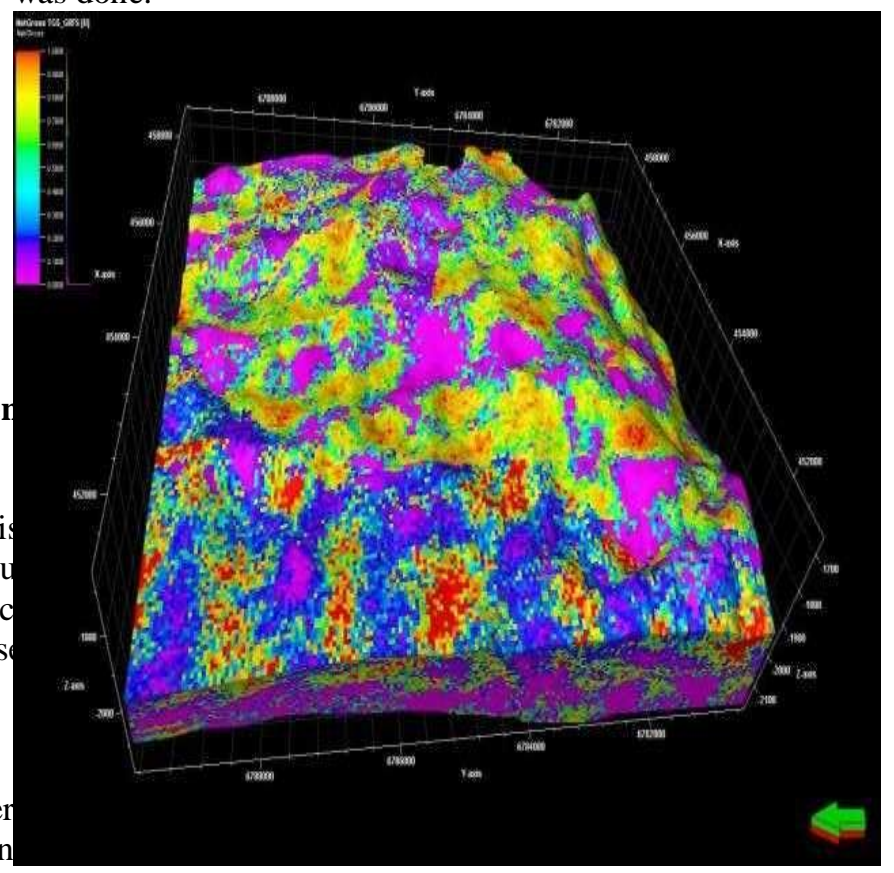

Eigure 5: Net to gross model using GRFS algorithm on nTGS with trend facies model 
A table for the worst-case, most likely, and best-case scenarios was derived from the uncertainty analysis and is shown below.

Table 1: Summarized result of P10, P50 and P90 ranking from uncertainty analysis

\begin{tabular}{llll}
\hline $\begin{array}{l}\text { ALGORITHM } \\
\text { COMBINATION }\end{array}$ & P10 & P50 & P90 \\
\hline SIS_KRIG & 36 & 38 & 42 \\
SIS_SGS & 40 & 74 & 100 \\
SIS_GRFS & 39 & 65 & 70 \\
\hline TGS_KRIG & 35 & 38 & 40 \\
TGS_GRFS & 36 & 46 & 63 \\
\hline TGS_SGS & 38 & 64 & 73 \\
\hline KRIG_KRIG & 37 & 37 & 37 \\
\hline
\end{tabular}

Sensitivity analysis was done in order to ascertain the relative impact of the different combined algorithm on hydrocarbon pore volume. The result is as seem in the tornado plot below

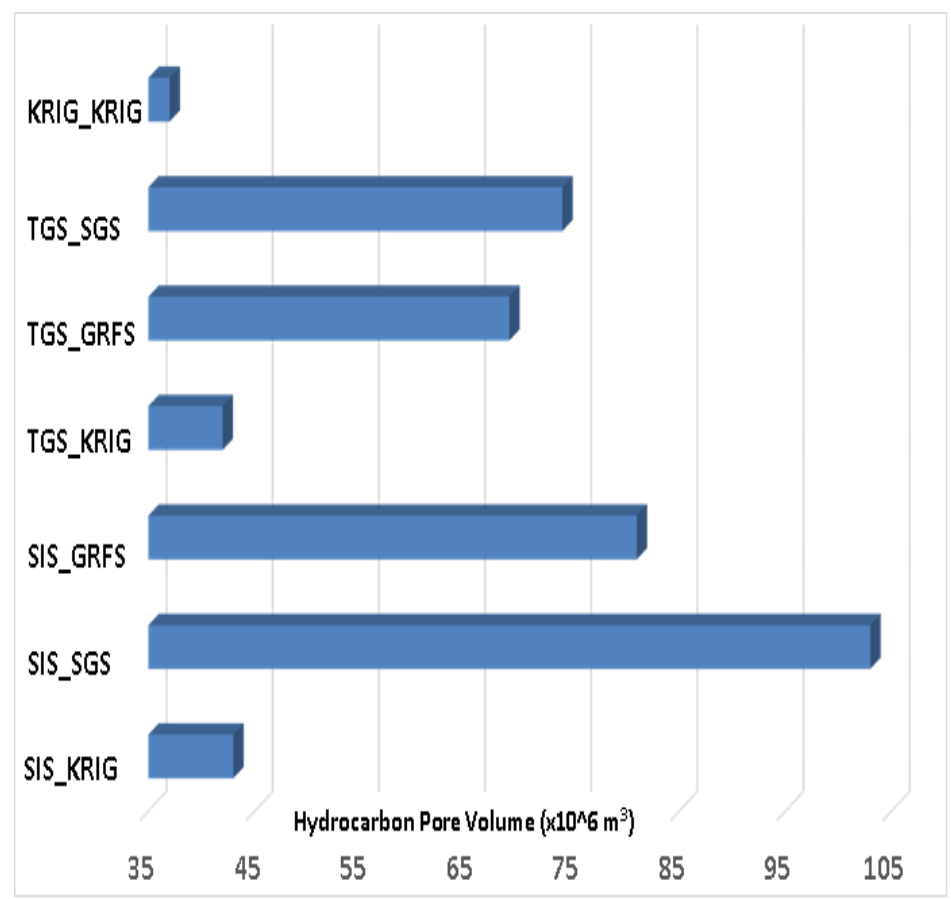

Figure 6: Tornado Plot of the range of volumes captured by the various modeling algorithm

\section{CONCLUSION}

Unique combinations of both the facies and petrophysical modeling algorithm have been used to build various realizations of static models and volumes were computed, which were subjected to
Monte Carlo simulation giving us a range of volume for each unique combination, then P10, P50, P90 can be identified and used for Field Development Plan (FDP). This was used to capture the range of uncertainties in these models. SIS_SGS gives the widest range of uncertainty while Krig_Krig gave the least (0) uncertainty.

\section{ACKNOWLEDGEMENT}

The authors of this work wish to acknowledge the Centre of Excellence in Geosciences and Petroleum Engineering, University of Benin, Nigeria and Schlumberger Information Solutions for providing data, technology and permission to publish results.

\section{REFERENCE}

1. Arild Hesjedal and Petter Eltivik- Statoil (2009). "Introduction to the Gullfaks area"

2. Falivene, O., Cabrera, L., Sáez, A., (2007) Optimum and robust $3 \mathrm{D}$ facies interpolation strategies in a heterogeneous coal zone (Tertiary As Pontes basin, NW Spain). International Journal of Coal Geology, 71(2-3), 185-208.

3. Fossen, H., \& Gabrielsen, R. H. (1996). Experimental modeling of extensional fault systems by use of plaster. Journal of Structural Geology, 18(5), 673-687

4. Fossen, H., and Hesthammer, J. (2000), possible absence of small faults in the Gullfaks Field, northern North Sea: implications for downscaling of faults in some porous Sandstone in Journal of Structural Geology 22 (2000) 851-863. Elsevier Science Ltd

5. Harms, J.C., Southard, J.B., Spearing, D.R., and Walker, R.G., (1975) Depositional environments as interpreted from primary sedimentary structures and stratification sequences: Society for Sedimentary Geology (SEPM) Short Course 9, 249 p.

6. Isaaks, E.J., Srivastava, R.M., (1989) An introduction to Applied Geostatistics. New York, Oxford University Press, $561 \mathrm{pp}$.

7. Petterson, 0. Storli, A., Ljosland, E. and Massie, 1. (1990) The Gullfaks Field: geology and reservoir development. In: North Sea Oil and Gas Reservoirs H. Norwegian Institute of Technology. Graham \& Trotman, London, 6790

8. Reynolds, A. D. (1995) Sedimentology and sequence stratigraphy of the Tbistle Field, northem North Sea. In Steel, R. J., Felt, V., Johannessen, E. P. \& Mathieu, C. (eds.): Sequence Stratigraphy on the Northwest European Margin, 257-271. Norwegian Petroleum Society Special Publication No. 5.

9. Schlumberger Property Modeling manual.

10. Selley, C. R (1998), Elements of petroleum geology, 2nd Edition, 470pp. Academic Press

11. Selley, R.C., (1978) Concepts and methods of subsurface facies analysis: American Association of 
Petroleum Geologists, Continuing Education Course Notes Series 9, $82 \mathrm{p}$

12. Structural geology of the Gullfaks field, northern North Sea H Fossen, J Hesthammer (1996): Special Publication-Geological Society of London 127, 231262

13. USGS Bullentin 2202-C, Kimmeridgian Shales Total Petroleum System of the North Sea Graben Province 